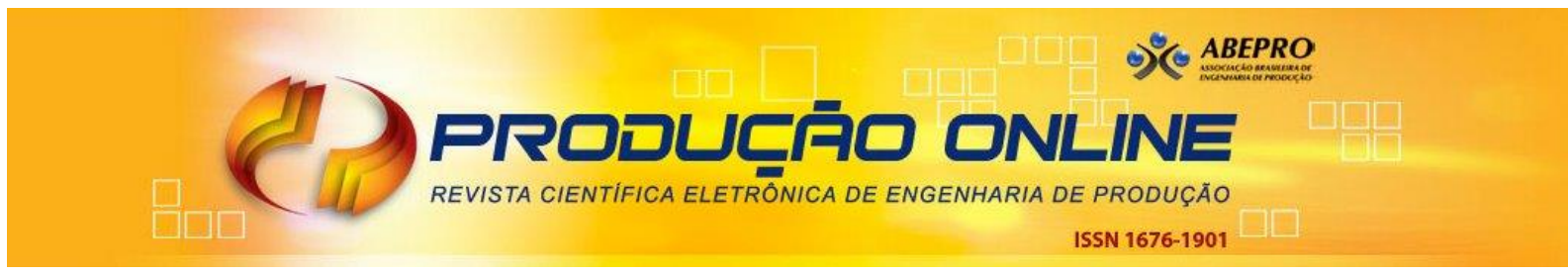

\title{
USO DO MÉTODO DE ANÁLISE HIERÁRQUICA PARA A AVALIAÇÃO DE COMPETITIVIDADE: UM ESTUDO DE CASO APLICADO EM UMA INDÚSTRIA DE CONFECÇÕES NO PARANÁ - BRASIL
}

\section{USE OF THE HIERARCHICAL ANALYSIS METHOD FOR COMPETITIVENESS EVALUATION: A CASE STUDY APPLIED IN A CLOTHING INDUSTRY IN PARANA STATE - BRAZIL}

\author{
Manoel João Ramos ${ }^{*}, * \star$ E-mail: eng.major@hotmail.com \\ Vanessa Andreia Sontag** E-mail: sontagvanessa94@gmail.com \\ Daniele Kern Prass ${ }^{\star *} E-m a i l:$ danieleprass@hotmail.com \\ Tatiane Gabriele Moraes ${ }^{*}$ E-mail: tatigmoraes19@gmail.com \\ * Universidade Estadual do Oeste do Paraná (UNIOESTE), Cascavel, PR \\ ** Faculdade de Ensino Superior de Marechal Cândido Rondon (ISEPE), Marechal Cândido Rondon,
} PR

Resumo: O processo de tomada de decisão baseia-se na necessidade da interação entre gestores com o intuito de obter uma melhor solução entre as possíveis alternativas. Desta forma este trabalho tem por objetivo apresentar uma escala de importância entre cinco critérios de desempenho associados a quinze alternativas para melhorar a competitividade empresarial. Portanto, foi utilizado como instrumento analítico o método AHP. Este ferramental multicritério auxilia na tomada de decisão e na solução de problemas complexos. O estudo de caso do tipo quali-quantitativo de caráter exploratório, foi desenvolvido em uma indústria de confecções localizada no Oeste do Paraná. O Estado abriga o segundo maior polo confeccionista do Brasil. Os resultados da pesquisa sugerem que os critérios de maior importância englobam qualidade e flexibilidade, ambos com $38 \%$ de representatividade. Em relação as alternativas de maior importância, os resultados indicam a facilidade de alterar a programação da produção com $71 \%$ de representatividade, seguido pelas alternativas de redução de falhas nos produtos e processos com $67 \%$ e a qualificação de mão de obra com $65 \%$ de representatividade entre às demais alternativas para alcançar a meta de melhorar o desempenho e a competitividade da empresa estudada.

Palavras-chave: Tomada de decisão. Competitividade. Método AHP.

Abstract: The decision making process relies on the necessity of interaction between managers aiming at the better solution among possible alternatives. Thus, the objective of this paper is to present an importance scale among five performance criteria combined with fifteen alternatives to improve business competitiveness. Therefore, AHP method was used as an analytical instrument. That multicriteria tool aids the decision making and the solution of complex problems. The case study is quali-quantitative with exploratory character. It was carried out in a clothing industry located in Western Parana state (Brazil). The state holds the second largest clothing pole in the country. The research results suggest that the most important criteria comprehend quality and flexibility, both with representativeness of $38 \%$. In regard to the most important alternatives, results point out the ease to altering production scheduling, with representativeness of $71 \%$, followed by alternatives of reduction of failures in products and processes with $67 \%$ and labor qualification with representativeness of $65 \%$ among the other alternatives to reach the goal of improving the company performance and competitiveness.

Keywords: Decision making. Competitiveness. AHP method. 


\section{INTRODUÇÃO}

A atividade de tomar decisões diante de múltiplas alternativas pode ser considerada uma tarefa comum na rotina de muitos gestores. Entretanto, esta tarefa crucial para as organizações, requer conhecimento, segurança e coerência. A todo instante, os gestores se deparam com situações em que é necessário decidir, optar, tomar uma posição frente a uma ou várias escolhas, desde as mais simples até as mais complexas. Isto pode influenciar significativamente na competitividade e no desempenho das organizações e, assim, trazer consequências boas ou ruins.

Conforme destacam Bana e Costa, Stewart e Vansnick (1995), a tomada de decisão é de fato parte integrante da vida cotidiana. Contudo, é uma atividade intrinsecamente complexa e potencialmente controversa, em que os procedimentos de escolha não se restringem apenas entre alternativas de ação, mas também entre pontos de vista e formas de avaliar essas ações, bem como, o fato de considerar toda uma multiplicidade de fatores direta e indiretamente relacionados com a decisão a tomar.

Da mesma forma, o processo de avaliação de desempenho pode ser considerado um desafio para as organizações, pois as informações necessárias nem sempre estão disponíveis, o que pode ampliar as incertezas e a insegurança para os gestores, além de dificultar os processos de tomada de decisão. Deste modo, a utilização de indicadores e métodos de apoio a decisão contribuem significativamente para um melhor desempenho organizacional, na medida em que permitem ampliar o enfoque em problemas avaliados como complexos.

Neste contexto, o objetivo desta pesquisa consiste em aplicar de forma empírica o método Analytic Hierarchy Process (AHP) para obter uma escala hierárquica, em ordem de maior importância, de um conjunto de indicadores relacionados aos objetivos de desempenho organizacional, com potencialidade para alavancar a competitividade de uma indústria do setor de confecções, localizada na região Oeste do Estado do Paraná, Brasil. Esta escala hierarquizada possibilita o ordenamento de ações, priorizando aquelas de maior importância para que se alcance as metas relacionadas a ampliar a competitividade da empresa estudada. 


\section{REVISÃO BIBLIOGRÁFICA}

\subsection{Estratégia e Competitividade}

Conforme descreve Moreira (2006), a administração da produção tem como base planejar, organizar, dirigir e controlar os recursos disponíveis para produção de bens e serviços, bem como atingir os objetivos estabelecidos. Além disso, a produção é diretamente influenciada pelo ambiente interno e áreas funcionais da empresa como marketing, finanças e os recursos humanos que são facilmente controlados pela organização. Por outro lado, os fatores externos exercem influência indireta e não podem ser controlados pelos gestores das organizações, estão relacionados com a política econômica do país, taxas de juros, inflação, redução de créditos, além das políticas governamentais que podem acelerar ou frear a produção, a competitividade entre empresas e os avanços tecnológicos que estão cada vez mais fortes e presentes no mercado.

A estratégia da produção é uma ferramenta utilizada pela empresa para definir prioridades adequadas e combinadas com a política e objetivo da instituição. Conforme conceitua Harding (1981, p. 28) "uma vez formulado o plano estratégico, é posto em operação por todas partes interessadas da empresa: marketing, finanças, planejamento de novos produtos e produção". Da mesma forma, Slack, Chambers e Johnston (2002), complementam que as estratégias podem ser definidas a partir do seu conteúdo e da habilidade do gestor em relacionar os objetivos da empresa às atividades da produção, bem como, o processo de elaboração da estratégia relacionada ao local em que a mesma será implementada e qual o método para atingir o objetivo da instituição.

Dois indicadores são considerados, especialmente, importantes para alcançar o sucesso produtivo: a eficiência e a eficácia, que garantem a competitividade. A eficiência consiste em fazer as coisas certas utilizando da melhor maneira possível os recursos disponíveis e a eficácia equivale em atingir os objetivos esperados formando excelência. Mas nem sempre é possível conciliar estes dois indicadores, pois a produção pode ser eficaz, mas não eficiente e vice-versa ou até ineficiente, no qual não atinge nenhum dos objetivos esperados (CHIAVENATO, 2005). 
[...] em termos de vantagens competitivas, uma empresa pode superar o desempenho de seus rivais somente se conseguir estabelecer uma diferença que possa ser mantida. Para este fim, a empresa deve buscar entregar o valor para o cliente de forma diferenciada, criar valor para a empresa ao menor custo ou fazer as duas coisas (CARVALHO e LAURINDO, 2010, p.19).

Desta forma, a competitividade pode se relacionar ao fato de a empresa ser mais produtiva, aumentando gradativamente o volume de sua produção, ao passo que reduz a utilização de recursos, seja por meio da melhoria nos procedimentos utilizados, nos equipamentos ou na mão de obra. A competitividade assegura que a empresa se mantenha no mercado. Entretanto, a empresa deve compreender as necessidades dos clientes, fazer uso de métodos sofisticados, estar disposto a desenvolver novos produtos, processos, saber administrar e gerenciar sistemas, comercializar adequadamente seus produtos e prestar assistência técnica caso ocorra algum problema (CAMPOS, 2004).

O processo para identificar quais competências a empresa precisa estruturar para ganhar vantagem competitiva, conforme destacam Carvalho e Laurindo (2010), é uma tarefa difícil, pois os gestores lidam com um mercado em constante mutação. Porém, desenvolver suas potencialidades é fator decisivo para uma posição de sucesso competitivo. É necessário habilidades produtivas e tecnológicas que se adaptem a empresa, para proporcionar um baixo custo de produção, agilidade nos processos, velocidade no ritmo produtivo e qualidade do produto, proporcionando assim, um diferencial competitivo em relação a seus concorrentes.

Destarte, pode-se dizer que a missão das organizações consiste em satisfazer as necessidades dos consumidores, os quais são a razão pela qual a empresa existe. As empresas produzem bens ou serviços para, posteriormente, serem desejados e cobiçados pelos clientes. Deste modo, o input (matéria-prima e insumos) deve ter o menor custo possível para ser transformado em output (produto acabado mediante a agregação de valor), que após obter um preço final deverá atender as necessidades dos consumidores. Vale ressaltar que, as saídas do processo produtivo em geral apresentam o produto final desejado, mas também, pode vir a apresentar produtos indesejáveis ou que não esteja de acordo com o que o cliente solicitou (CAMPOS, 2004). 


\title{
2.2 Tomada de Decisões
}

As pessoas são, diariamente, envolvidas em processos de tomada de decisões. Porém, no ambiente empresarial, este processo é abrangido pela complexidade e dificuldade, perante um elevado número de variáveis, dados imprecisos ou incompletos e até mesmo objetivos conflitantes. Além de incluir custos e a necessidade de atendimento aos anseios das pessoas, a tomada de decisão no ambiente empresarial e competitivo, exige-se do tomador de decisão maior nível de sabedoria e inteligência emocional ao lidar com as possíveis consequências (MARQUES, 2018).

Para Moreira (2006, p.25), "a tomada de decisão envolve uma situação problema, onde o gerente se depara com várias alternativas de solução". Desta forma, este mesmo autor salienta a importância da utilização de técnicas que ajudam a avaliar todas possibilidades para compreensão total das necessidades e busca da melhor alternativa e, destaca ainda, a relevância do uso de dados quantitativos e qualitativos como ferramentas de apoio a decisão.

\begin{abstract}
Uma decisão é uma escolha entre alternativas ou possibilidades. As decisões são tomadas para resolver problemas ou aproveitar oportunidades. O processo de tomar decisões (ou processo decisório) é a sequência de etapas que vai da identificação de um problema ou oportunidade, até a escolha e colocação em prática de uma ação ou solução (MAXIMIANO, 2011, p. 85).
\end{abstract}

Conforme argumenta Maximiano (2011), o processo de tomar decisões está interligado as tarefas de liderar, planejar, organizar, executar e controlar. Saber tomar as decisões é a principal função do administrador da empresa, pois não existe decisão ideal, ele tem a responsabilidade de pesar as vantagens e desvantagens de cada alternativa para escolher a melhor, sempre visando agregar renda a sua empresa.

O processo de tomada de decisão conhecido como administrativo ou intuitivo considera que uma decisão tomada "no calor do momento", aparentemente, sem a utilização de um sistêmico raciocínio lógico, sendo a decisão baseada na intuição e na experiência do decisor. Por vezes, este tomador de decisão poderá procurar informações adicionais até atingir um nível de conforto desejado. Por outro lado, na 
tomada de decisão racional, a informação existente sobre uma determinada situação é a mais completa possível, sendo este volume de informação processado por meio de um processo lógico e racional que visa alcançar a melhor decisão possível mediante o emprego das informações disponíveis (STURGES e MINOR, 2002). Este autor salienta ainda, que a tomada de decisão organizacional mistura os dois estilos, o racional e o administrativo.

Neste contexto, Thomaz (2005) argumenta que os atuais processos de tomada de decisão baseiam-se na racionalidade limitada e na necessidade de incorporar fatores como a interação dos gestores em grupo, o conhecimento dos sistemas de valores e as características das ações, numa perspectiva construtiva e de aprendizagem sobre o problema, com o intuito de obter uma melhor solução entre as possíveis alternativas, construindo desta forma uma solução de compromisso.

\subsection{Critérios para melhoria no desempenho}

O intuito das organizações é atingir os objetivos e metas para satisfazer os clientes da maneira mais eficiente e eficaz, com o propósito de sobressair ao concorrente. Ao realizar uma ação com eficiência está fazendo certo as coisas, ou seja, realiza o processo com qualidade para garantir o mínimo de satisfação, com otimização de tempo e recursos disponíveis. Já a eficácia é atingir os objetivos e resultados previstos pela organização (CORRÊA, 2005).

Barros Neto, Fensterseifer e Formoso (2003), consideram que ao avaliar o desempenho é preciso que esteja de acordo com as estratégias de produção, com base em critérios competitivos que influenciam na tomada de decisão. São classificados em dois critérios: os qualificadores de pedido, que possuem o mínimo exigido pelo mercado com o mínimo de desempenho e os ganhadores de pedido que possuem melhor performance que a concorrência. Conforme Wilker (2018), as operações precisam satisfazer os stakeholders, formadas por um grupo de pessoas que têm interesse na empresa, representados pela sociedade, acionistas e funcionários, estes esperam que suas necessidades sejam atendidas. Para que as 
organizações realizem este feito se atribui os cinco objetivos de desempenho compostas pela qualidade, rapidez, confiabilidade, flexibilidade e custo.

Desempenhar as funções com qualidade é um objetivo fundamental para a sobrevivência das corporações e muitas vezes fator determinante na decisão de compra do cliente. Qualidade é realizar de modo certo as coisas e está diretamente ligada à satisfação ou insatisfação das pessoas, pois seu atributo fundamental é fornecer bens e serviços isentos de falhas. Esta propriedade tem como função diminuir os custos e o tempo de retrabalho, de modo consequente menor irritação e estresse por parte da empresa e clientes. Além do mais, proporcionará maior confiabilidade aos consumidores e vantagem competitiva comparado a seus rivais (SLACK, CHAMBERS e JOHNSTON, 2002).

Para Garvin, citado por Corrêa (2005), a qualidade possui oito dimensões: desempenho principal do produto; características do produto; confiabilidade; conformidade de acordo com as especificações; durabilidade; manutenção fácil e de baixo custo; estética e a qualidade percebida que envolve sentimentos ligados a forma de atendimento e entendimento subjetivo sobre qualidade.

Executar ações de maneira mais rápida possível, diminui o tempo de espera do cliente, desde o início do ciclo produtivo até seu término. Contribui ainda, com agilidade na movimentação interna, redução de estoques no estágio de processamento e possíveis riscos. Deste modo, ao prover agilidade o empreendimento aumenta a oferta de produtos e serviços aos consumidores proporcionando, capacidade maior que seus concorrentes em resposta aos consumidores e na entrega do produto final (WILKER, 2018).

Em relação ao atributo de confiabilidade, Slack, Chambers e Johnston (2002, p.74), argumentam que "significa fazer as coisas em tempo para os consumidores receberem seus bens ou serviços prometidos". Este fator pode ser determinante na decisão do cliente no decorrer do tempo, pois não importa o quão barato seja o produto se ele não chega no tempo previsto a necessidade do usuário. Conforme aumenta a confiabilidade se obtém agregação de valor ao produto, diminuição no período gasto para reprogramar os serviços, e ainda, aumento na economia de dinheiro e estabilidade. 
Quanto ao critério de flexibilidade, Slack, Chambers e Johnston (2002), definem como a capacidade de estar em constante adaptação e modificações das operações. Isto pode ocorrer por meio da habilidade desenvolver e modificar mercadorias, possuir ampla variedade no composto de produtos e serviços, quantidade do volume produzido e flexibilidade na entrega, para atender ao pedido do cliente. E ainda, reagir de forma positiva em situações imprevistas mantendo qualidade nos bens e serviços. As vantagens são compostas de agilidade na resposta, economia de tempo e confiabilidade.

Para as empresas que disputam por preços baixos, o fator custo será o principal objetivo. Quanto menor as despesas com mão de obra, instalações, equipamentos, matéria-prima para produzir, maior será a lucratividade (SLACK, CHAMBERS e JOHNSTON, 2002). Deste modo, para atingir o efeito desejado e boa performance com redução de gastos, é indispensável melhorar o desempenho da qualidade, rapidez, confiabilidade e flexibilidade, devido ao reflexo que proporcionam umas com as outras e, assim, melhorar a competitividade da organização.

\section{PROCEDIMENTOS METODOLÓGICOS}

Para a realização deste estudo foi utilizado como instrumento de coleta de dados um processo de discussão junto aos gestores da empresa objeto de pesquisa, mediante uma entrevista semiestruturada contendo vinte questões, as quais foram elaboradas no intuito de avaliar como a equipe de gestores viabilizam o processo de melhoraria no desempenho produtivo e, assim, alcançar maior competitividade. O instrumento foi aplicado no segundo semestre de 2018 nas dependências da empresa à cinco colaboradores que exercem cargos de liderança. Este procedimento inicial permitiu a definição de um conjunto de critérios e alternativas a serem avaliadas e julgadas como prioritárias para o processo de ampliação da competitividade e melhoria de desempenho da empresa. De forma complementar, buscou-se na literatura o conjunto de critérios que poderiam nortear a definição do conjunto de alternativas, as quais foram elencadas mediante a discussão com o grupo de líderes. 
Como técnica de pesquisa, aplicou-se o método Analysis Hierarchical Process (AHP) que consiste em uma modelagem quantitativa e estruturada de análise de decisão multicritérios, desenvolvida por Thomas Saaty para avaliar problemas tecnológicos, econômicos, sociopolíticos e complexos.

Conforme define Saaty (1991), o método AHP consiste em uma ferramenta de apoio à decisão multicritério, baseada em três princípios, tais como na construção de uma hierarquia; no estabelecimento de prioridades; e na consistência lógica das prioridades. O processo decisório tem por objetivo selecionar as melhores alternativas baseadas em múltiplos critérios, para realizar a escolha adequada. Ao definir critérios e alternativas os decisores deparam-se com diferentes opiniões, que devem ser analisadas, pois podem contribuir ou dificultar o resultado desejado. (TEKNOMO, 2006).

Para Vargas (1990), o método AHP têm como finalidade identificar um problema e sua possível solução, sua aplicação se dá em dois momentos: no primeiro ocorre a estruturação do problema a ser melhorado de forma hierárquica, bem como a definição do objetivo principal, critérios, subcritérios e alternativas para avaliação (figura1). No segundo momento, os tomadores de decisão avaliam as possibilidades através da comparação, par a par, de acordo com os níveis de maior importância ou contribuição para que se atinja a meta estabelecida.

Figura 1 - Ilustração Hierárquica

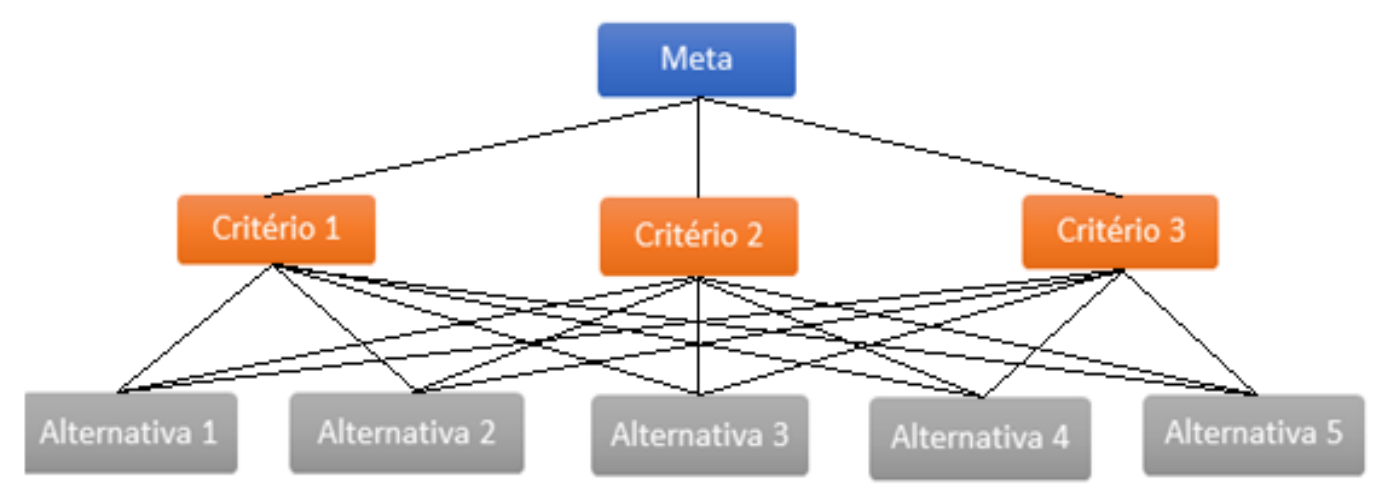

Fonte: Adaptado de Saaty (2008) 
Neste sentido, após a estruturação hierárquica que representa os problemas a serem solucionados ou metas a serem alcançadas, os critérios e as alternativas a serem hierarquizadas é aplicado de modo subjetivo a determinação de pesos numa escala de 1-9 de acordo com o grau de maior importância (VARGAS, 1990).

Para a avaliação pareada, aplicou-se para o desenvolvimento deste estudo, uma segunda entrevista junto a equipe de liderança para mensurar o grau de importância de cada alternativa, respeitando o índice de consistência, conforme estipula o método proposto por Saaty (tabela 1 ).

Tabela 1 - Escala de números para julgamentos comparativos

\begin{tabular}{cccc}
\hline $\begin{array}{c}\text { Grau de } \\
\text { importância }\end{array}$ & $\begin{array}{c}\text { Definição de } \\
\text { importância }\end{array}$ & Explicação \\
\hline 1 & Igual & A duas funções contribuem igualmente para o objetivo. \\
3 & Razoável & A experiência e o entendimento favorecem levemente uma \\
atividade sobre a outra.
\end{tabular}

Fonte: Adaptado de Saaty \& Vargas (2013)

Os comparativos descritos na tabela 1 determinam o grau de importância em relação aos demais critérios, em que o elemento mais importante é numerado com valor inteiro e de menos importância com valor fracionado, conforme representado no quadro 1. Neste processo, a resolução da matriz expõe que os elementos da linha A e coluna $A$ são iguais a 1 , situados em diagonal. Os elementos-linha são mais dominantes do que os elementos-coluna, pois são maiores que 1. Assim, a linha $A$ é 6 vezes mais predominante que a coluna $C$, já a linha $C$ é 8 vezes mais atuante que a coluna $D$. 
Quadro 1 - Matriz comparativa

\begin{tabular}{|c|c|c|c|c|}
\hline & $\mathrm{A}$ & $\mathrm{B}$ & $\mathrm{C}$ & $\mathrm{D}$ \\
\hline $\mathrm{A}$ & 1 & 5 & 6 & 7 \\
\hline $\mathrm{B}$ & $1 / 5$ & 1 & 3 & 4 \\
\hline $\mathrm{C}$ & $1 / 6$ & $1 / 3$ & 1 & 8 \\
\hline $\mathrm{D}$ & $1 / 7$ & $1 / 4$ & $1 / 8$ & 1 \\
\hline
\end{tabular}

Fonte: Matoshima (2015)

A partir deste procedimento, mediante o lançamento dos valores atribuídos pelos julgadores em uma planilha previamente desenvolvida no formato Excel® já se obteve os resultados da pesquisa que por seguinte foram tabulados e processados para reproduzirem as tabelas e gráficos ilustrativos.

Conforme determina Saaty (1991) para melhores resultados as matrizes são elevadas a uma potência alta. Neste processo é realizado a soma de cada linha e a divisão dos elementos da matriz pelo total da coluna, no qual, resulta no auto vetor de prioridades por meio da média aritmética dos elementos de cada linha da matriz. Quando definido o grau de importâncias relativas aos critérios é testado a integridade da avaliação, calculada através do índice de inconsistência. Este índice não pode ser maior que 0,10 . Caso ocorra, deverá ser reavaliado a decisão para tornar consistente os resultados, assim a relação deve ser igual ou menor que 0,10.

De acordo com Vargas (2010), para calcular o maior autovalor da matriz de julgamento ( $\mathrm{M} \mathrm{Max})$ através do somatório do total de cada coluna j da matriz original, por cada elemento na posição j do vetor de prioridade (Eigen), considerando j a coluna da matriz de julgamento variando de 1 a $\mathrm{n}$. Considerando a matriz a seguir, com o vetor de prioridades dos elementos e a ordem (n) da matriz, já o Tj é a soma da coluna j da matriz e Pj é a prioridade calculada para o critério da linha j, deste modo, o cálculo do autovalor é representado pela seguinte fórmula:

$\lambda M a x={ }^{n} \sum T j \times P j$

$J=1$

A seguir é calculado o índice de consistência $(\mathrm{Cl})$, representado pela seguinte fórmula: 
$C l=\lambda M a x-n \div n-1$

Já o cálculo para a razão de consistência, Consistency Ratio (CR) é representado a seguir:

$C R=C l \div R l<0,10$

O valor de $(\mathrm{RI})$ é fixo e tem como base o número de critérios avaliados, determinado na tabela 2 a seguir:

Tabela 2 - Identificação do índice de consistência aleatória

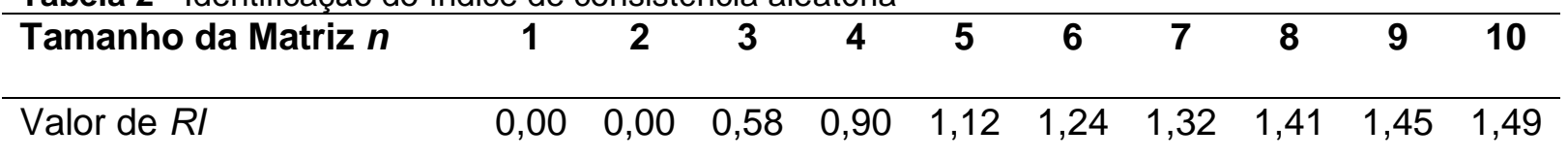

Fonte: Saaty (1991).

\section{RESULTADOS E DISCUSSÃO}

Mediante a definição da meta global, dos objetivos, dos critérios e das alternativas foi possível estruturar o problema de forma a orientar a aplicação do método AHP. A figura 2 apresenta a estruturação do modelo hierárquico para o problema proposto sendo composta pelo objetivo principal, cinco critérios relacionados aos objetivos de desempenho (custo, qualidade, rapidez, confiabilidade e flexibilidade), cada qual possui três alternativas que totalizam quinze possibilidades na hierarquia de importância. Estas alternativas foram definidas na discussão junto ao grupo de liderança da empresa pelo grau de relevância embasado nos objetivos de desempenho, sendo necessário uma definição quanto a prioridade e ordenação das alternativas que deverão ser primeiramente atendidas para que se tenha êxito no objetivo proposto. 
Figura 2 - Estrutura hierárquica do objeto proposto

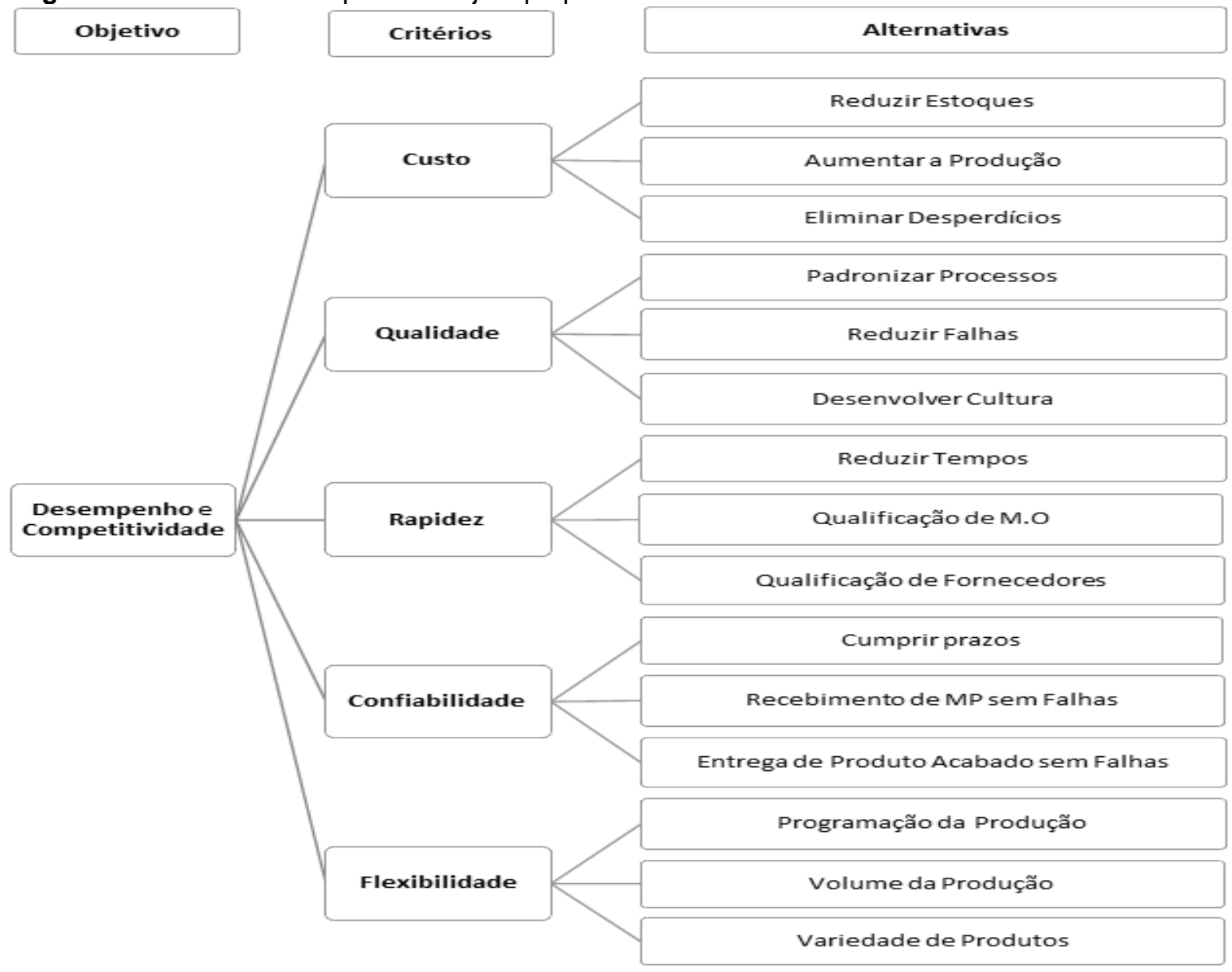

Fonte: Dados da pesquisa (2018).

Definido o método AHP como mecanismo usado no processo de apoio a tomada de decisão e identificação dos interesses diante das alternativas, para o desenvolvimento da competitividade, seguiu-se então, este modelo como uma forma de melhorar os processos da empresa. Portanto, foi realizado uma análise inicial dos critérios adotados, para facilitar o processo de julgamento utilizando uma planilha de cálculo no Excel, para registrar os valores de importância nas comparações pareadas.

Conforme resultados ilustrados no gráfico 1, foram analisados de forma pareada os cinco critérios previamente definidos. Fica evidente que o critério qualidade representou uma participação de $38 \%$ para que se alcance a meta de melhoraria no desempenho e competitividade da empresa, conforme o julgamento dos avaliadores. Isto implica na realização de procedimentos que resultem em uma 
produção sem falhas, de modo a satisfazer os consumidores. Já a flexibilidade, apresenta-se no mesmo nível de importância, destacando que a empresa deve estar preparada para alterar a programação da produção e reagir ao inesperado mantendo o mesmo tratamento ao cliente. Em seguida, o critério de rapidez, custo e confiabilidade apresentam-se com graus de menor relevância.

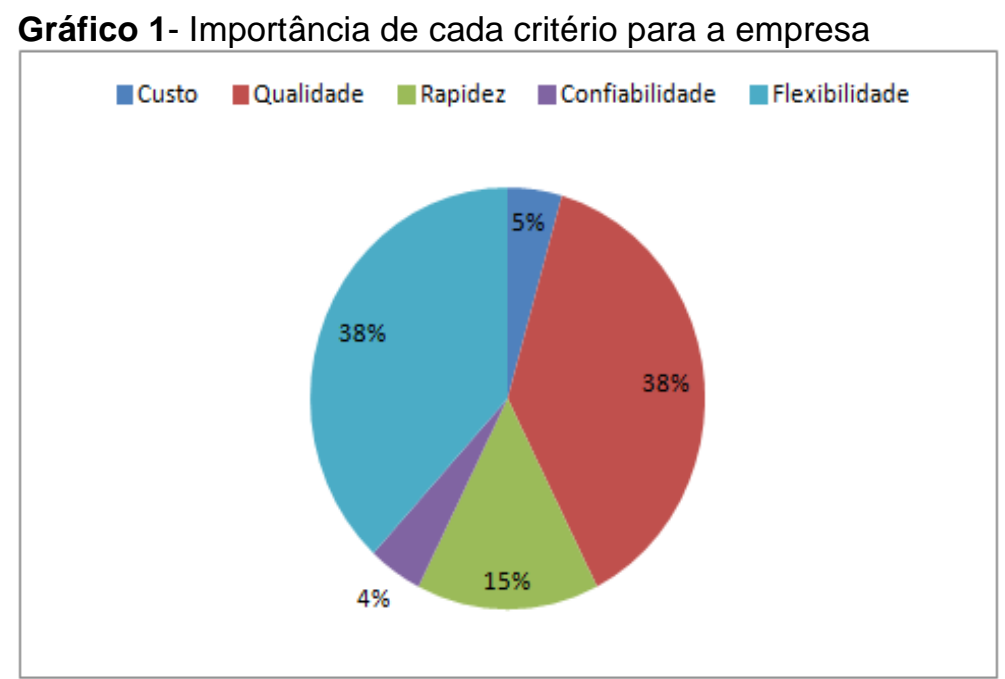

Fonte: Dados da pesquisa (2018).

Nos processos seguintes, os dados foram tratados mediante a avaliação pareada dentro de cada critério com base nas alternativas propostas.

\subsection{Critério de Custo}

Em relação ao critério custo, os resultados indicam a necessidade de a empresa estabelecer procedimentos que visem a eliminação dos desperdícios, sendo esta a alternativa mais relevante para que se alcance a meta de melhoria de desempenho e competitividade, com representação de $71 \%$ perante as outras alternativas relacionadas a tal critério (tabela 3 , gráfico 2). Desta forma, entende-se que sob a ótica dos líderes, a eliminação de desperdícios contribui de forma muito mais representativa para a melhoria do desempenho e competitividade da empresa do que um possível aumento no volume de produção ou na redução do volume de matérias e produtos estocados. 
Tabela 3 - Comparação pareada das alternativas relacionadas ao critério custo

\begin{tabular}{lccc}
\hline & Reduzir Estoques & Aumentar Produção & Eliminar Desperdícios \\
\hline Reduzir Estoques & 1,00 & 2,00 & 0,20 \\
Aumentar Produção & 0,50 & 1,00 & 0,20 \\
Eliminar Desperdícios & 5,00 & 5,00 & 1,00 \\
\hline Sum( $\left.\boldsymbol{S}_{c i}\right)$ & $\mathbf{6 , 5 0}$ & $\mathbf{8 , 0 0}$ & $\mathbf{1 , 4 0}$ \\
\hline
\end{tabular}

Fonte: Elaboração dos autores (2018)

Gráfico 2 - Peso dos critérios com base no objetivo global

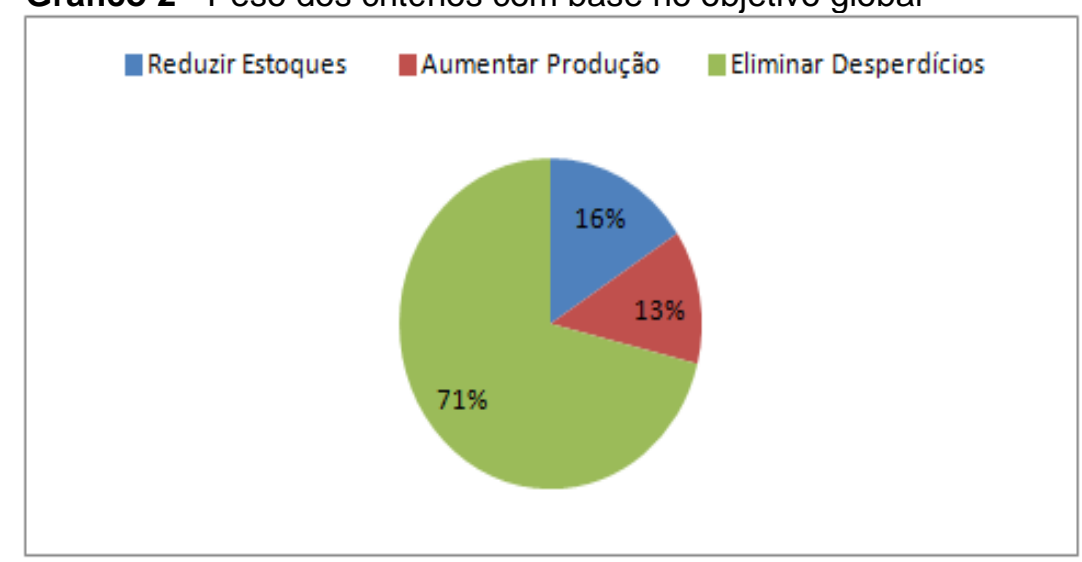

Fonte: Dados da pesquisa (2018).

O desperdício, conforme argumenta Elias e Magalhães (2003), pode ser entendido como qualquer atividade que absorve recursos, mas que não cria valor. Já o valor consiste na capacidade de oferecer um produto/serviço no momento certo a um preço justo e adequado, conforme esperado pelo cliente. Destarte, a base teórica da produção enxuta determina que a eliminação dos desperdícios possibilita reduzir os custos de produção e maximizar a satisfação do cliente.

Neste contexto, Ohno (1997), ressalta as sete principais causas de desperdícios (ou perdas) que devem ser identificadas e eliminadas pelas empresas: superprodução de mercadorias desnecessárias; espera, dos funcionários pelo equipamento de processamento para finalizar o trabalho ou por uma atividade anterior; movimentação e transporte desnecessário de mercadorias; processamento desnecessário, devido as inadequações de projetos de ferramentas e produtos; estoque à espera de processamento ou consumo; movimento desnecessário de pessoas; e produzir produtos defeituosos.

\subsection{Critério de Qualidade}

Em relação ao critério qualidade, os resultados indicam como alternativa prioRevista Produção Online. Florianópolis, SC, v. 20, n. 4, p. 1246--1169, 2020. 
ritária para a melhoria do desempenho e competitividade da empresa a tomada de ações direcionadas a redução das falhas no processo produtivo, com uma participação de $67 \%$ sobre as demais alternativas. Embora, a empresa tenha a preocupação em reduzir as falhas em todo o seu processo, para entregar um produto de qualidade, conforme a expectativa do cliente, os julgadores mencionam que esta, ainda é uma alternativa que necessita de melhoria contínua. A padronização de processos se apresenta como a segunda alternativa com uma participação de $21 \%$. Os avaliadores destacam a necessidade de a empresa implementar um método no processo de trabalho, possibilitando um aumento na organização das atividades e, consequentemente, ampliar a sua produtividade e reduzir as falhas decorrentes. Desse modo, o sistema automatizado contribui para a redução de erros ou falhas humanas.

Tabela 4 - Comparação pareada das alternativas relacionadas ao critério qualidade

\begin{tabular}{lccc}
\hline & Padronizar processos & Reduzir falhas & Desenvolver cultura \\
\hline Padronizar processos & 1,00 & 0,29 & 3,00 \\
Reduzir falhas & 3,50 & 1,00 & 5,00 \\
Desenvolver cultura & 0,33 & 0,20 & 1,00 \\
\hline Sum $\left(\boldsymbol{S}_{\boldsymbol{c}}\right)$ & $\mathbf{4 , 8 3}$ & $\mathbf{1 , 4 9}$ & $\mathbf{9 , 0 0}$
\end{tabular}

Fonte: Elaboração dos autores (2018).

Gráfico 3 - Peso dos critérios com base no objetivo global

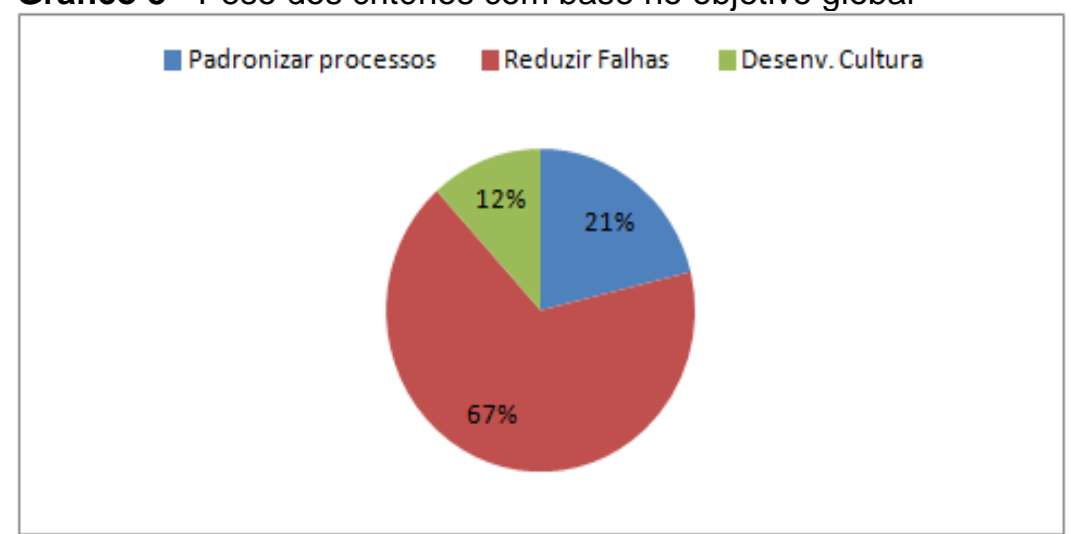

Fonte: Dados da pesquisa (2018).

Conforme destacam Aguiar e Salomon (2007), uma empresa que realiza pouco investimento em prevenção, geralmente, irá concentrar seus esforços em tratativas relacionadas as falhas no processo produtivo, ou até no mesmo para ressarcir prejuízos ao seu cliente final. Este tipo de estratégia acaba por afetar a 
imagem da empresa distanciando-a, cada vez mais, de um bom desempenho no mercado competitivo. Por outro lado, quando uma empresa decide investir de maneira eficaz na prevenção de falhas, os retornos são certos na redução de custos.

\subsection{Critério de Rapidez}

Conforme ilustrado no gráfico 4, foram analisados de forma pareada as três alternativas relacionadas ao critério rapidez. Os resultados apontam que a alternativa de qualificação da mão de obra contribui com $65 \%$ para alcançar a meta de desempenho e competitividade, quando comparadas com as demais alternativas relacionadas ao critério rapidez.

Tabela 5 - Comparação pareada das alternativas relacionadas ao critério rapidez

\begin{tabular}{lccc}
\hline & Reduzir tempos & Qualif. Mão de Obra & Qualif. Fornecedores \\
\hline Reduzir tempos & 1,00 & 0,20 & 0,33 \\
Qualif. Mão de Obra & 5,00 & 1,00 & 3,00 \\
Qualif. Fornecedores & 3,00 & 0,33 & 1,00 \\
\hline Sum $\left(\boldsymbol{S}_{\boldsymbol{c}}\right)$ & $\mathbf{9 , 0 0}$ & $\mathbf{1 , 5 3}$ & $\mathbf{4 , 3 3}$ \\
\hline
\end{tabular}

Fonte: Elaboração dos autores (2018).

Gráfico 4 - Peso dos critérios com base no objetivo global

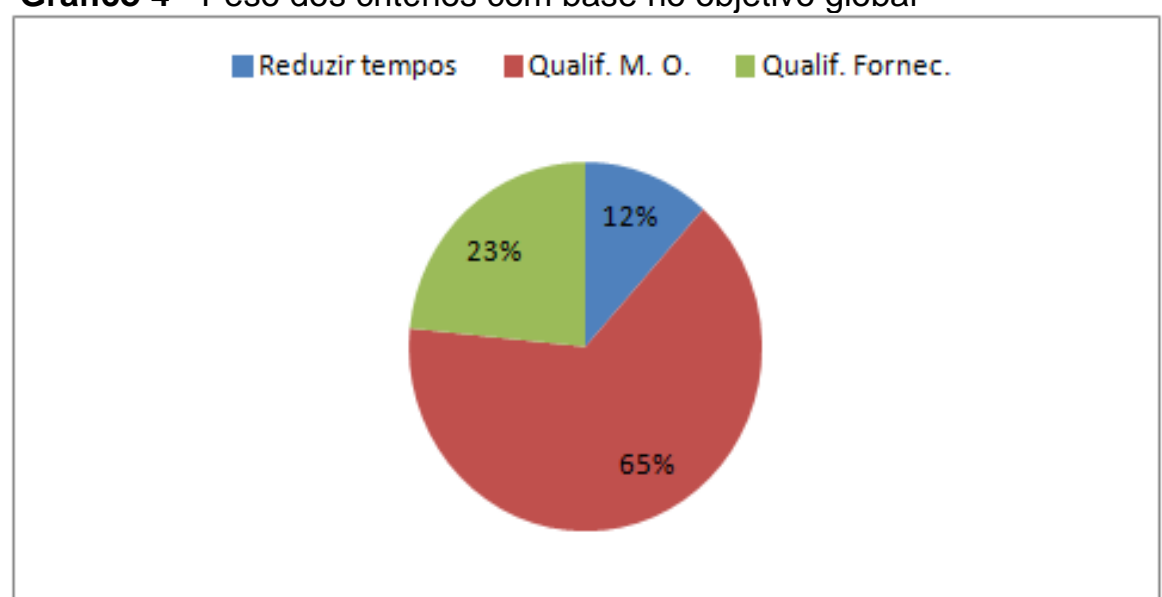

Fonte: Dados da pesquisa (2018).

Por meio da capacitação dos colaboradores e comprometimento da equipe, os julgadores avaliam que é possível garantir melhorias significativas na produtividade $\mathrm{e}$, consequentemente, trazer bons resultados na busca pela excelência e desempenho competitivo. Da mesma forma, avaliam que a partir da 
escolha de uma mão de obra adequada e qualificada pode-se alcançar a redução de tempo no processo produtivo.

Em relação ao objetivo de desempenho rapidez, Slack, Chambers e Johnston (2002), abordam este critério como o tempo transcorrido entre o pedido e entrega do produto pelo cliente. Sendo a velocidade na entrega dos produtos ao cliente, um fator de grande importância.

\subsection{Critério de Confiabilidade}

De acordo com os resultados obtidos, o fator mais importante no requisito de confiabilidade para a empresa é a entrega de produtos acabados (PA) sem falhas, 0 que representa 74\% quando comparado às demais alternativas (gráfico 5).

A empresa mantém uma preocupação constante em entregar o produto sem falhas, mas avalia pouco representativo os critérios restantes. Deve-se ressaltar que a entrega um produto acabado sem falhas, muitas vezes, é proveniente do recebimento de matéria prima de acordo com as especificações, ou seja, livre de falhas. O contrário, embora permita correções no processo produtivo, pode contribuir para delongas na atividade de produção e gerar atrasos na entrega, pois para alcançar prazos é preciso entregar o pedido no tempo certo de acordo com a solicitação dos consumidores. Isso trará maior confiabilidade e estabilidade para a organização.

Tabela 6 - Comparação pareada das alternativas relacionadas ao critério confiabilidade

\begin{tabular}{lccc}
\hline & Cumprir prazos & Receb. MP s/ Falhas & Entreg. PA s/ Falhas \\
\hline Cumprir prazos & 1,00 & 3,00 & 0,20 \\
Receb. MP s/ Falhas & 0,33 & 1,00 & 0,14 \\
Entreg. PA s/ Falhas & 5,00 & 7,00 & 1,00 \\
\hline Sum $\left(\boldsymbol{S}_{\boldsymbol{c}}\right)$ & $\mathbf{6 , 3 3}$ & $\mathbf{1 1 , 0 0}$ & $\mathbf{1 , 3 4}$
\end{tabular}

Fonte: Elaboração dos autores (2018). 
Gráfico 5 - Peso dos critérios com base no objetivo global

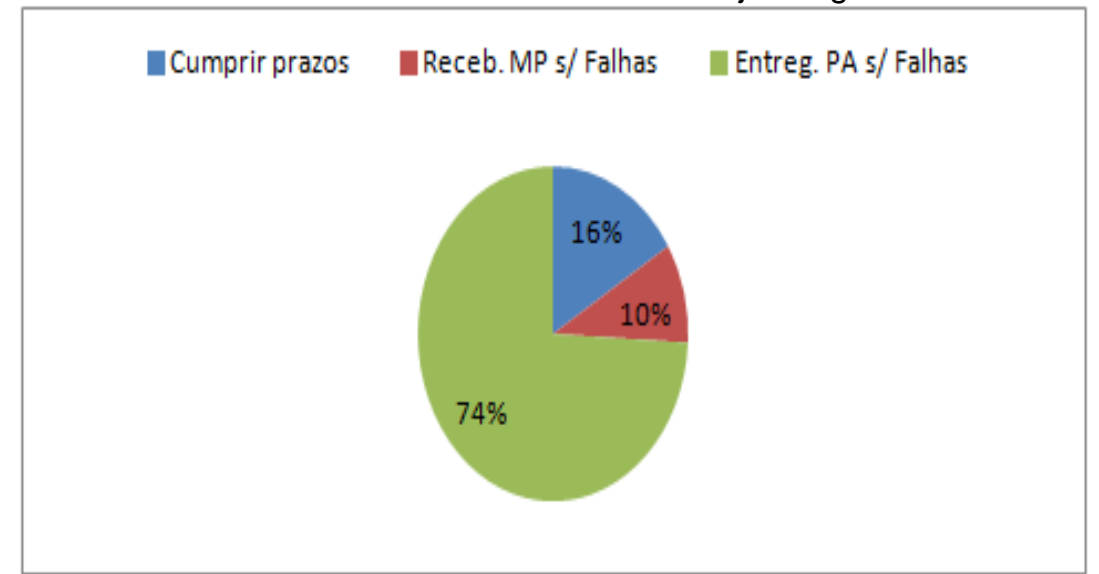

Fonte: Dados da pesquisa (2018).

Para Slack, Chambers e Johnston (2002), a confiabilidade permite a estabilidade e, caso a produção não atenda a esse objetivo, o desempenho a ser apresentado nos demais objetivos poderão ser insatisfatórios.

\subsection{Critério de Flexibilidade}

Em relação ao critério de flexibilidade entre as alternativas propostas estão: facilidade para alterar a programação da produção, flexibilidade no volume de produtos vendidos e variedade de produtos vendidos. Conforme resultados apresentados no gráfico 6 , a possibilidade de alterar o plano de produção com facilidade se destaca com $71 \%$ entre as demais alternativas para o alcance do objetivo de melhoria de desempenho e competividade. Isso significa que esta alternativa contribui cinco vezes mais que a alternativa volume de produtos quando comparadas aos pares para o alcance da meta estabelecida. A flexibilidade consiste na capacidade de os sistemas produtivos responderem as regras de mercado, introduzindo novos produtos, novos processos e, consequentemente, alavancar o desempenho competitivo da empresa.

Para Tubino (1997), o setor de planejamento e controle da produção deve manter um relacionamento direto com todas as áreas que envolvem a empresa como: Engenharia de Produto, Engenharia do Processo, Marketing, Manutenção, Compras/Suprimento, Recursos Humanos e Finanças, pois são estes os setores 
responsáveis em abastecer a produção com recursos fundamentais para segmento do processo produtivo.

Tabela 7 - Comparação pareada das alternativas relacionadas ao critério flexibilidade

\begin{tabular}{lccc}
\hline & Progr. Produção & Volume Produção & Variedade Produtos \\
\hline Progr. Produção & 1,00 & 5,00 & 5,00 \\
Volume Produção & 0,20 & 1,00 & 0,50 \\
Variedade Produtos & 0,20 & 2,00 & 1,00 \\
\hline Sum $\left(\boldsymbol{S}_{\boldsymbol{c}}\right)$ & $\mathbf{1 , 4 0}$ & $\mathbf{8 , 0 0}$ & $\mathbf{6 , 5 0}$
\end{tabular}

Fonte: Elaboração dos autores (2018).

Gráfico 6 - Peso dos critérios face ao objetivo global

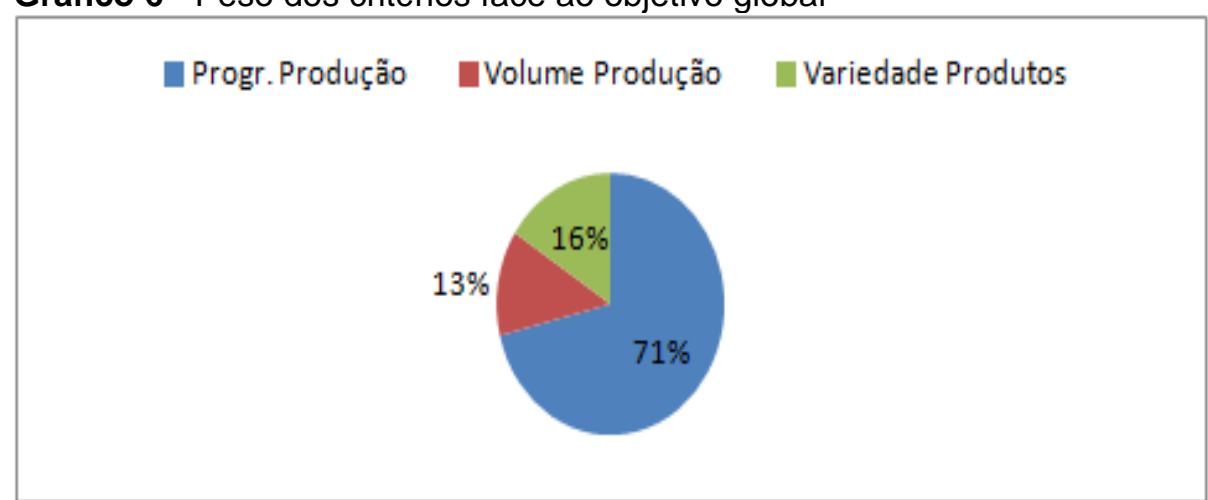

Fonte: Dados da pesquisa (2018).

Por fim, ao fazer uma avaliação entre todas as quinze alternativas, verifica-se que a facilidade em alterar a programação da produção figura-se como a alternativa de maior importância (22,7\%) para a indústria de confecções analisada neste estudo de caso, quando o objetivo principal consiste em melhorar o desempenho e competitividade da empresa. Na sequência a alternativa de maior destaque é necessidade vislumbrada pelos gestores em reduzir o volume de falhas e retrabalhos, que apresenta um resultado de $21,3 \%$ de representatividade entre as demais alternativas.

Embora a programação da produção seja considerada uma atividade de extrema importância para a indústria têxtil, avalia que cabe a este setor obter informações do estoque, ajustar a produção, os pedidos e verificar a capacidade produtiva. Qualquer falha que ocorrer nesta área implicará no restante dos processos. Já na alternativa de redução de falhas é preciso fazer uma análise das ocorrências e verificar a necessidade de automatizar processos para melhores 
resultados. Isso traria impactos positivos na qualidade dos produtos e contribuiria para a redução de custos operacionais.

Entre as alternativas menos relevantes estão o recebimento de matéria prima sem falhas com representatividade de apenas $0,4 \%$ que se refere a um controle de qualidade na recepção, trocas e utilização do material. Na sequência apresenta-se a alternativa de aumentar os volumes de produção com apenas $0,5 \%$ em relação as demais alternativas quanto ao grau de importância, pois primeiramente, é necessário maior controle nos setores produtivos, para evitar irregularidades para então buscar aumento produtivo.

Gráfico 7 - Ranking das alternativas consideradas mais importantes pela Indústria de confecções com base na melhoria desempenho para alcançar competitividade

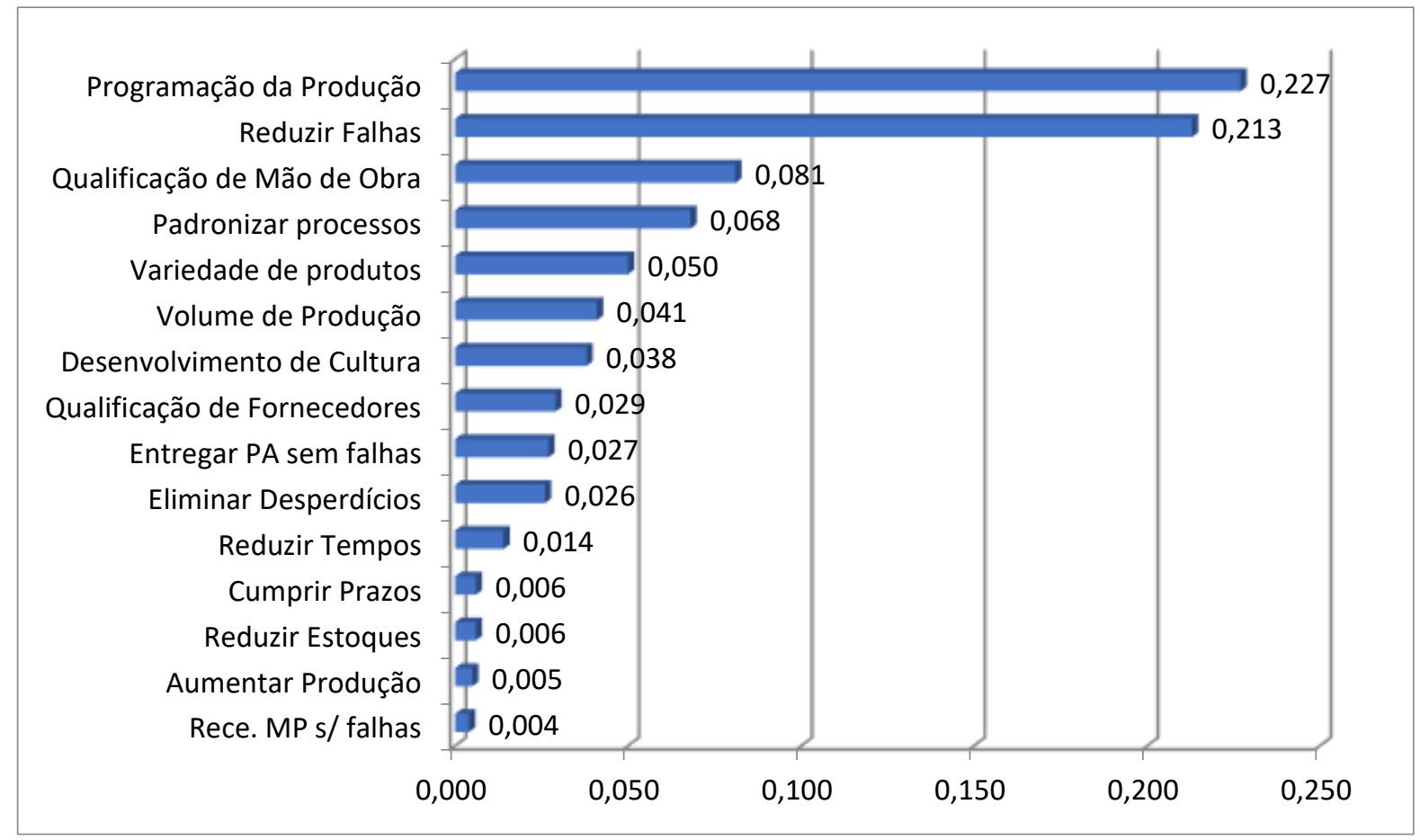

Fonte: Dados da pesquisa (2018).

\section{CONSIDERAÇÕES FINAIS}

Saber tomar a decisão correta é de fundamental importância para manter o bom desempenho produtivo e a competitividade da empresa. Portanto, se faz necessário considerar a relevância deste processo na definição de critérios e alternativas que servirão de base para alcançar objetivos e metas complexas. Desta forma, a aplicação do método AHP possibilitou identificar sua importância como 
ferramenta de auxílio à tomada de decisão. A partir dos resultados obtidos com o uso do método hierárquico definiu-se algumas prioridades entre um rol de alternativas a serem trabalhadas para buscar um melhor desempenho. Também foi possível estabelecer uma análise de consistência que permite avaliar o grau de assertividade nos julgamentos, e assim, evitar possíveis falhas no processo de avaliação das alternativas.

Neste contexto, os resultados obtidos refletem a opinião dos colaboradores envolvidos no processo, que também são tomadores de decisão, o que possibilita um melhor engajamento da equipe em uma possível implementação das alternativas escolhidas. Com base na análise dos resultados pode se visualizar ainda, que em relação aos critérios, o de maior importância englobam a Qualidade e a Flexibilidade com representatividade $38 \%$ cada critério. A manutenção da qualidade é um quesito primordial para as empresas e consumidores, pois muitas vezes é o fator de decisão para o consumidor no processo de escolha de um produto em detrimento de outro. Da mesma forma, a flexibilidade para a organização tem sua importância em estar em constante adaptação em relação a imprevistos que podem ocorrer durante o processo produtivo ou no atendimento ao cliente.

Por fim, ao definir a ferramenta aponta a importância da Programação da Produção diante do planejamento de insumos, controle, direcionamento dos itens produzidos em relação à previsão da demanda, para evitar desperdícios, atingir satisfação do cliente e ampliar a competitividade. Já a redução de falhas demonstra a preocupação da empresa em entregar o melhor produto para o cliente final, atendendo as expectativas como forma de ganhar mercado. De forma complementar, a qualificação da mão de obra proporciona melhor capacitação dos funcionários, como consequência possibilita o aumento da produtividade, maior envolvimento, comprometimento e desempenho da equipe e melhor rendimento operacional. Uma possível atuação de melhoria nestas três alternativas principais pode impactar positivamente para o melhor desempenho competitivo da empresa.

\section{REFERÊNCIAS}

AGUIAR, D. C.; SALOMON, V. A. P. Avaliação da prevenção de falhas em processos utilizando métodos de tomada de decisão. Production, v. 17, n. 3, p. 502519, 2007. http://dx.doi.org/10.1590/S0103-65132007000300008 
BANA E COSTA C. A.; STEWART, T. J.; VANSNICK, J. C. Multicriteria decision analysis: some throughts based on the tutorial and discussion sessions of the esigma meetings. 14th. European Conference on Operational Research, iul. 1995.

BARROS NETO, J. P.; FENSTERSEIFER, J. E.; FORMOSO, C. T. Os critérios competitivos da produção: um estudo exploratório na construção de edificações. Revista de Administração Contemporânea, v. 7, p. 67-85, 2003. http://dx.doi.org/10.1590/S1415-65552003000100004

CAMPOS, V. F. Gerenciamento da rotina do trabalho do dia-a-dia. 9. ed. Nova Lima: INDG Tecnologia e Serviços Ltda, 2004.

CARVALHO, M. M. de; LAURINDO, F. J. B. Estratégia Competitiva: os conceitos de implementação. 2. ed.São Paulo: Atlas, 2010.

CHIAVENATO, I. Administração de produção: uma abordagem introdutória. 16 reimp. Rio de Janeiro: Elsevier, 2005.

CORRÊA, H. L; CORRÊA, C. A. Administração da produção e de operações: manufatura e serviços uma abordagem estratégica. São Paulo: Atlas, 2005.

ELIAS, S. J. B.; MAGALHÃES, L. C. Contribuição da Produção Enxuta para obtenção da Produção mais limpa. Revista Produção online, v.3, n.4, p. 1-8, 2003. https://doi.org/10.14488/1676-1901.v3i4.577

HARDING, H. A. Administração da Produção. Trad. José Marques Jr. São Paulo: Atlas, 1981.

MARQUES, J. R. A importância da tomada de decisões nas organizações. Disponível em: https://www.ibccoaching.com.br/portal/a-importancia-da-tomadadedecisoes-nas-organizacoes/. Acesso em: 05 ago. 2018.

MATOSHIMA, M. Aplicação do método do processo de análise hierárquica na priorização de produtos e comparação dos clusters chineses e do Arranjo Produtivo Local de Maringá - Cianorte nos Setores Têxtil e do Vestuário. 78 f. Monografia. (Graduação em Engenharia de Produção) - Universidade Estadual de Maringá, Maringá, 2015.

MAXIMIANO, A. C. A. Introdução à administração. 8. ed. São Paulo: Atlas, 2011. MOREIRA, D. A. Administração da produção e operações. São Paulo: Thomson Learning, 2006.

OHNO, T. O Sistema Toyota de produção. Porto Alegre: Artes Médicas, 1997.

SAATY, T. L. Método de análise hierárquica. São Paulo: Makron Books, 1991, 367p. 
SAATY, T. L. Relative measurement and its generalization in decision making: why pairwise comparisons are central in mathematics for the measurement of intangible factors. The Analytic Hierarchy Process. Madrid: Review of the Royal Spanish Academy of Sciences, 2008. http://www.rac.es/ficheros/doc/00576.PDF. https://doi.org/10.1007/BF03191825

SAATY, T. L.; VARGAS, L. G. Models, methods, concepts and applications of the Analytic Hierarchy Process. London: Springer New York, Heidelberg Dordrecht London, 2013. https://doi.org/10.1007/978-1-4614-3597-6

SLACK, N.; CHAMBERS, S.; JOHNSTON, R. Administração da produção. Trad.Maria Teresa Corrêa de Oliveira e Fábio Alher. 2. ed. São Paulo: Atlas, 2002.

STURGES, D. L., MINOR, M. Total quality communication customer decisionmaking. Communication Policy and Strategy Class, University of Texas-Pan American, Edinburgh, TX, 2002.

TEKNOMO, K. Analytic Hierarchy Process (AHP) tutorial, 2006. Disponível em: file://C:/Users/Usu\%C3\%A1rio/Downloads/AHP Tutorial.pdf. Acesso em: 11 de ago. 2018.

THOMAZ, J. P. C. F. Apoio a tomada de decisão na avaliação do desempenho de pessoas: contributos para o processo de decisão militar em tempos de paz. Tese (Doutorado em Engenharia e Gestão Industrial) - Universidade Técnica de Lisboa, Instituto Superior Técnico (IST), Portugal, 2005.

TUBINO, D. F. Manual de planejamento e controle da produção. São Paulo: Atlas, 1997.

VARGAS, L. G. An overview of the Analytic Hierarchy Process and its applications. European Journal of Operational Research. North-Holland, v. 48, p. 2-8, nov. 1990.

VARGAS, R. Utilizando a programação multicritério (AHP) para selecionar e priorizar projetos na gestão de portfólio, em PMI Global Congress - North America, 2010, Washington - EUA. Disponível em: http://www.ricardovargas.com/articles/analytic-hierarchy-process/\#portuguese. Acesso em: 24 out. 2018. https://doi.org/10.1016/0377-2217(90)90056-H

WILKER, B. Objetivos de Desempenho da Produção. Disponível em: http://www.bwsconsultoria.com/2010/01/os-objetivos-de-desempenhodaproducao.html. Acesso em: 06 ago. 2018.

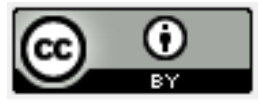

Artigo recebido em: 08/11/2018 e aceito para publicação em: 05/12/2020 DOI: http://dx.doi.org/10.14488/1676-1901.v20i4.3436 